\title{
LA GUERRA DE MALVINAS Y SUS TRINCHERAS INTELECTUALES: ENTREDICHOS ENTRE LOS EDITORES DE LA REVISTA SITIO Y EL ESCRITOR NÉStor Perlongher
}

\author{
Exequiel Svetliza
}

La última dictadura militar argentina, que se instauró en el país con el golpe de Estado del 24 de marzo de 1976, impuso un contexto represivo donde cualquier voz de disenso suponía la posibilidad concreta de ser censurado por los órganos del Estado, pero también el peligro inminente de ser condenado a la muerte o al exilio. En el análisis y la descripción que Beatriz Sarlo (1988) hace del campo intelectual (BOURDIEU, 2002) argentino durante la dictadura, caracteriza a ese espacio social como un espacio doblemente fracturado. Por un lado, el régimen militar había clausurado la circulación de discursos críticos, escindiendo a los intelectuales de la sociedad, separándolos de aquellos estratos populares donde hasta entonces habían circulado muchas de sus ideas. Por otro lado, muchos intelectuales y artistas abandonaron el país en un contexto en donde el exilio -fuese voluntario o inducido por las fuerzas represivasse imponía como forma de preservar la vida. Esto generó una separación tajante entre aquellos que se quedaron y los que se fueron, produciendo, de esta manera, un nuevo resquebrajamiento que trazaba los límites de un adentro y un afuera del campo intelectual:

En 1976 se nos expulsaba de la intervención política, se clausuraba la esfera pública y se nos imponía una doble fractura. Al exilio de nuestros amigos e interlocutores, que cortaba el campo intelectual en un adentro y afuera, se añadió la segregación de los intelectuales y artistas en una burbuja casi 
hermética, alejada, por evidentes razones de represión y las correlativas estrategias de seguridad para la supervivencia, de los espacios populares, igualmente asolados por la violencia estatal. La dictadura militar cortó el tejido social que había hecho posible la circulación de ideas y la comunicación con otros espacios. (SARLO, 1988, p. 101)

El régimen militar había logrado con éxito fragmentar el campo intelectual, generando divisiones profundas que se pusieron de manifiesto, sobretodo, en la discusión que se suscitó en aquellos años entre los que se quedaron en el paísy los que sevieron obligados al exilio ${ }^{1}$. De esta manera, al atomizar el campo prácticamente se anuló toda posibilidad de circulación de ideas, pensamientos y debates que pudieran llegar a configurar formas de disenso para la dictadura. En este contexto, al conocerse la noticia de la recuperación de las islas Malvinas por parte de la Junta Militar el 2 de abril de 1982, fueron pocas las voces que pudieron sortear la censura y la represión del régimen para expresar una visión crítica respecto a la operación militar en el archipiélago. De hecho, en la mayor parte de los casos, se trató de una serie de discursos que debieron ampararse en el anonimato para poder eludir el velo informativo y preservar la integridad de los emisores ${ }^{2}$. De esta manera, ante las condiciones impuestas en el país, esos discursos estaban condenados a una circulación prácticamente clandestina, subterránea.

Es evidente que la recuperación y posterior guerra por la soberanía de las islas Malvinas significó un momento de crisis para la sociedad argentina. En este contexto, surgieron distintos posicionamientos intelectuales que, más temprano que tarde, entraron en abierta confrontación. En un momento histórico donde se había vuelto prioritario entender qué era lo que estaba sucediendo, discutir ideas y posturas era, a su vez, una necesidad. El conflicto bélico había alentado entonces a la recomposición de algunos canales de diálogo entre aquellas zonas del campo intelectual

\footnotetext{
${ }^{1}$ Una de las polémicas más recordadas en torno a la cuestión los que se fueron/los que se quedaron fue la que desarrollaron los escritores Julio Cortázar y Liliana Heker entre 1978 y 1980, en la cual el escritor de Rayuela, entonces exiliado en Francia, se había referido a la situación del campo intelectual argentino durante la dictadura como un "genocidio cultural" (PAVÓN, 2008).

${ }^{2}$ Como fue el caso de los documentos de circulación anónima: Paz inmediata y negociación: única victoria del pueblo, con fecha del 26 de mayo de 1982 producido por un grupo de siete intelectuales residentes en Argentina: Beatriz Sarlo, Carlos Altamirano, Luis Príamo, Jorge Goldenberg, Juan Pablo Renzi, María Teresa Gramuglio y Luis Novalesi (SARLO, 2014); y el texto titulado ¿La verdad o la mística nacional? escrito por el periodista Carlos Brocato y que circuló como un folleto firmado por el Círculo Espacio Independiente (SUÁREZ, 2007).
} 
que se habían visto sesgadas en los primeros años de la dictadura, particularmente, la de los intelectuales en el exilio. Beatriz Sarlo va a ubicar el inicio de ese proceso un tiempo antes de la guerra, aunque parece claro que fue el conflicto de Malvinas el escenario que mejor propició la reanudación del debate:

\begin{abstract}
Hacia 1980, comenzaron a reestablecerse los lazos con esa otra zona del campo cultural argentino que vivía en el exilio. De la polarización silenciosa e incluso resentida, se pasó a polémicas abiertas que, pese a repetir clisés signados por una inevitable antigüedad, cumplieron la función de hacer público el debate y, por lo tanto, abrieron un espacio donde éste podía llegar a desarrollarse de manera más productiva. (1988, p. 106)
\end{abstract}

Mientras dentro del país la instauración del debate se tornaba dificultosa, desde afuera, proliferaban argumentos que se posicionaban a favor y en contra de la recuperación militar de las islas. Si bien la discusión se generaba entre intelectuales o grupos de intelectuales desperdigados por distintas partes del mundo a causa del exilio, la polémica tenía como principal campo de batalla el terreno simbólico de la nación. En las islas, los soldados argentinos, agazapados en sus pozos de zorros, se batían con un enemigo que avanzaba entre la turba malvinera. Afuera del archipiélago y de la guerra real, el combate argumental en el cual se debatían los auténticos significados de esas batallas en donde se mataba o se moría, se libraba a una distancia que separaba tanto a los contendientes entre sí, como a estos del verdadero epicentro del conflicto. A los intelectuales en el exilio, reconoce el filósofo argentino León Rozitchner (2005), no les quedaba más que ser convidados de piedra en esa guerra que les era lejana, pero no ajena. Con la maquinaria bélica ya en marcha, sus fuerzas simbólicas poca o ninguna influencia podían ejercer en el desarrollo real de los acontecimientos. Sin embargo, aquellos que asumían el compromiso de pensar, de adoptar posturas y defenderlas y de atacar los argumentos contrarios, ocupaban sus posiciones en el territorio imaginario de la nación; esa nación de la que habían sido desterrados:

(...) estamos también nosotros en una guerra de posiciones donde la frase es barricada y el epíteto un misil. El proyectil de acero y fuego estalla en la batalla con su poder real que aniquila la vida; la palabra escrita, para no ser menos, estalla a su manera con su terror simbólico y aniquila al opositor con la sugerencia de su traición. (ROZITCHNER, 2005, p. 43) 
Proponemos la metáfora de las trincheras intelectuales para caracterizar a algunas de las posiciones asumidas dentro de un campo intelectual devenido en simbólico campo de batalla; campo que fue el escenario de polémicas donde se ponían en juego -como en el tablero de la estrategia bélica- alianzas y traiciones especulativas en las que parecía dirimirse la pertenencia o no a la nación. Tomamos para nuestro análisis una de las polémicas que consideramos más significativas entre aquellas que se produjeron durante el desarrollo e inmediatamente después del conflicto bélico. Se trata de la discusión que tuvo como escenario a la revista cultural argentina Sitio y de la que participaron los directores de la publicación y el escritor Néstor Perlongher desde Brasil. Podemos leer en esta confrontación un relato que se configuraba como el terreno de una disputa simbólica. Por sus principales características formales, se evidencia una clara filiación de este tipo de discusión con el ensayo; género discursivo al que podemos describir sintéticamente como un enunciado en prosa que expresa el punto de vista personal y subjetivo del autor respecto a un tema específico (ESTÉBANEZ CALDERÓN, 1996). Los estudiosos del ensayo han destacado la gran flexibilidad del género en cuanto a sus formas, extensión y temas; además de señalar la clara voluntad de estilo del ensayista como una de sus características determinantes (BUENO MARTÍNEZ, 1964). Entendemos a los textos que conforman la polémica analizada como instancias subjetivas de enunciación donde confrontan dialógicamente no sólo diferentes posicionamientos respecto a la cuestión Malvinas, sino también distintas formas y estilos literarios.

\section{NÉSTOR PERLONGHER VS SITIO}

Esta batalla argumentativa tuvo como escenario las páginas de la revista cultural argentina Sitio. La publicación existió entre 1981 y 1987 con una producción de apenas seis números que tuvieron una periodicidad bastante irregular ${ }^{3}$. Sin embargo, se trató de una revista significativa en cuanto sirvió como el espacio donde se desarrollaron distintas discusiones del campo intelectual y literario en tiempos en que las voces críticas eran escasas, dado el contexto del terrorismo de Estado y sus efectos en

\footnotetext{
${ }^{3}$ El primer número de la revista se publicó en diciembre de 1981, el segundo en noviembre de 1982, el tercero en septiembre de 1983, el cuarto y el quinto (edición doble) en mayo de 1985 y el sexto en mayo de 1987.
} 
el ámbito de la cultura. En consecuencia, la emergencia de Sitio fue un síntoma, por un lado, del marcado relajamiento de las operaciones de censura y represión del régimen militar hacia el campo intelectual ${ }^{4}$ (a comienzos de la década del ochenta y tras la aniquilación de los grupos revolucionarios, era evidente que la principal preocupación de la dictadura estaba en la creciente crisis económica que atravesaba el país). Por otro lado, de la cercanía inminente de una etapa de transición democrática, lo que suponía tanto una revisión crítica del programa revolucionario de la izquierda, como también la necesidad de un reposicionamiento de los intelectuales en su respectivo campo. La revista, dirigida inicialmente por Ramón Alcalde, Eduardo Grüner, Luis Gusmán, Jorge Jinkis, Mario Levin y Luis Thonis, contaba además con la participación asidua de un grupo de colaboradores, entre los que se destacaban: Osvaldo y Leónidas Lamborghini, Néstor Perlongher, Arturo Carrera, Enrique Pezzoni, Luis Chitarroni y Silvia Molloy, entre los más frecuentes. Desde sus comienzos se había perfilado como una revista de escritores donde proliferaban el ensayo y la poesía como géneros predominantes. Se podía percibir en sus páginas un intento de ruptura, tanto con los lenguajes como con el canon literario vigente; así la caracteriza Roxana Patiño, al destacar:

(...) una voluntad de cruce de textualidades residuales, coloquiales y eruditas, un trabajo implacable con los significantes, recorre este discurso neo-barroco (o neo-barroso, como lo definiría Perlongher) que invade y corrompe los discursos consolidados, sociales o literarios. (2006)

A esta estética de ruptura que podríamos interpretar como un gesto vanguardista, se suma, como rasgo distintivo de la publicación, una manifiesta propensión al debate y al intercambio de ideas. Esto se evidencia, desde el primer número, en la renuncia del editorial como voz unívoca de la revista. En cambio, cumplen con esta función tres textos escritos por Jorge Jinkis, Eduardo Grüner y Luis Gusmán. Antes que una

\footnotetext{
${ }_{4}^{4}$ Una clara muestra del debilitamiento de la censura impuesta por el régimen militar está en que, en su edición número 12 (de julio-octubre de 1981), la revista cultural Punto de Vista -que había comenzado a publicarse en marzo de 1978 y que constituyó uno de los principales espacios de resistencia de los intelectuales a la dictadura durante ese período en el país - publicó por primera vez un editorial en donde se produce el revelamiento de la verdadera identidad de sus artífices. Hasta entonces, la dirección de la revista se consignaba a Jorge Sevilla (un seudónimo utilizado para preservar la seguridad de los autores), función que pasaría a desarrollar Beatriz Sarlo. A su vez, también se revelaban los nombres de los integrantes del Consejo de Dirección: Carlos Altamirano, María Teresa Gramuglio, Ricardo Piglia, Hugo Vezzetti y la propia Sarlo.
} 
declaración de principios programáticos, se trata de discusiones que ellos denominan como "entredichos"; palabra que da cuenta de aquello que puede ser escrito y leído entre líneas, como también de una confrontación polémica de discursos. Los autores se van a encargar de explicitar esa postura:

Las notas que siguen llevan firmas para no sugerir un autor colectivo. Tratan de asuntos ya juzgados, prejuzgados y que, sin embargo, todavía despiertan pasiones y provocan silencios. Asuntos que volvimos a discutir entre todos, a sacudir, a poner en entredicho mientras hacíamos la revista. (1981, p. 3)

Por su parte, en su texto inaugural, Jinkis destaca esa heterogeneidad característica del coro de voces que conforman Sitio y la posibilidad de que este propicie un diálogo dentro del espacio de la revista, pero también hacia afuera:

Si la disparidad no se resuelve en eclecticismo, tampoco se reconocerá una "marca de la casa": la discusión aquí abierta se puede prolongar en cualquier parte y puede retornar a la revista desde cualquier parte. Sólo que abrir una discusión no es como se dice para dejar abiertas las cuestiones sino para situarlas mejor. Nuestras diferencias sólo se disimulan durante el tiempo de goce de algunos odios compartidos. (1981, p.5)

Ante el silenciamiento que impone el contexto hostil de la época, Sitio, como su nombre mismo parece indicar, propone un espacio de discusión en donde se disputan sentidos. En la publicación, ese lugar es ocupado principalmente por los mencionados "Entredichos", especie de sección que no es estática ni fija cuyo contenido Maximiliano Crespi describe como:

(...) textos escritos bajo la convicción que lo entredicho es ante todo soportado por un cuerpo concreto y dirigido a otros cuerpos concretos. Textos que responden a una coyuntura específica y que se definen fundamentalmente tanto por un deseo de comprensión como por un 'no poder callar'. (2010, p. 178)

Este será entonces el espacio elegido para discutir la guerra de Malvinas; el territorio donde los directores de la revista y el escritor Néstor Perlongher, exiliado en Brasil, libran su batalla discursiva. Esta polémica, al contar con el espacio de la revista como teatro de operaciones en común, se representaba como una disputa con trincheras apostadas en un mismo terreno. Aun cuando entre los contrincantes mediaba la distancia y la condición de exiliado de Perlongher, la lucha tiene la apariencia de una pelea cuerpo a cuerpo, de una confrontación entre contendientes 
que empuñan las palabras como bayonetas caladas que se esgrimen unos contra otros.

De los textos individuales que conforman los "Entredichos" del primer número, la revista pasa en la edición siguiente a un único entredicho; un texto grupal que reúne las firmas de quienes dirigen esa publicación: Ramón Alcalde, Eduardo Grüner, Luis Gusmán, Jorge Jinkis, Hugo Savino y Héctor Grisafi. Ese entredicho, que abre la edición, lleva el título de Las Malvinas argentinas. Del trabajo a la guerra y de la guerra al trabajo. ¡Argentinos a recomponer!, y tiene fecha del 5 de noviembre de 1982. Ese viraje hacia el sujeto colectivo que evitaban enfáticamente constituir en la publicación inaugural, aparece determinado por la coyuntura excepcional del conflicto bélico y pareciera negar la condición ensayística del texto, ya que las subjetividades adoptan ahora la forma de una expresión programática común. Sin embargo, debe entenderse esta manifestación conjunta no como una operación de ocultamiento de las distintas autorías individuales, sino como la representación de una autoría unificada. Los autores afirman que la mayoría de los textos que integran la edición ya habían sido redactados en el momento en que se produce la recuperación militar de las islas, pero la conmoción que les genera la guerra los obliga a emitir esa declaración y a repensar el rol de la revista en ese nuevo contexto:

Supimos que habíamos entrado en guerra, y que Sitio, durante un tiempo que no podíamos calcular, pero imaginábamos largo, era imposible revista literaria. Setenta y cuatro días después, la guerra había terminado. Apenas comenzábamos a pensar qué lugar le tocaba -o tenía que hacerse- una revista literaria en el seno de un pueblo en guerra. (1982, p. 4)

Existe en los autores la convicción de que la guerra supone un punto de inflexión, un episodio que impondrá necesariamente nuevas relaciones entre el hacer literario y la sociedad. Ellos se plantean explícitamente su papel en el campo cultural de la postguerra. Se preguntan qué hará la literatura con la guerra, como también qué harán ellos con la literatura:

Para nosotros, las guerras habían sido, fundamentalmente, testimonios orales o hechos literarios. Ahora nosotros, en guerra, pasábamos a ser un hecho del que la literatura tendría que dar cuenta. La guerra -imaginábamos- forzosamente nos dejaría en relaciones sociales nuevas (por momentos las suponíamos fundantes, inaugurales), y nos preguntábamos qué función dentro de ella nos tocaría cumplir. Materia nueva clamando por formas nuevas; nosotros no seríamos los mismos, habría otros lectores, otras conciencias, otro acceso a 
ellas; otros objetivos; ¿quizás una nueva eficacia? Ciertamente, un nuevo deber ser. (1982, p. 4)

Para intentar responder a la primera cuestión, esto es: qué hará la literatura con la guerra, el entredicho procede a la crítica de las primeras expresiones literarias que ha legado el conflicto bélico. Se trata de dos poemas publicados durante el desarrollo de la contienda armada: "Juan Lópezy Juan Ward” de Jorge Luis Borgesy “Cambalache” de Osvaldo Rossler. Los autores indagan en el discurso literario buscando algunas claves que les permitan una comprensión del suceso histórico traumático, de ahí que rechacen ser parte del nosotros que enuncia Borges (1982) en el cierre de su poema: "El hecho que refiero pasó en un tiempo que no podemos entender". Ellos van a conjurar esa imposibilidad de entendimiento que postula el poeta, justamente, porque lo que quieren es comprender. Sin embargo, su principal preocupación parece puesta en la segunda de las cuestiones: qué hacer con la literatura. Esa praxis literaria que ellos concebían como una práctica estetizante y rupturista con respecto a los discursos consolidados parecía desajustarse con las nuevas necesidades impuestas en el contexto de la postguerra; no encajaba ni encontraba su lugar:

Más que ninguno -o no menos que cualquier otro- proyecto argentino que no fuera matar o morir, la literatura quedaba aplazada. O por lo menos la literatura en el sentido habitual del término, la que Sitio hasta ese momento en pequeña parte generaba y la asumía toda: la de la exacción, la de la atrocidad, la del oprobio, la de 1976-1981. Toda ella: la intersticial; la que impávida; la amorosa del Fatum; la cifrada; la ladina; la autografiable en Expolibro; la subviertediscursos; la de la exhibición reservada o prudencial; la exilial; la tontuela; la coeditable; la jackobsina; la neobarroca; la laconniana; la antibúmica; la capitular: la Nuestra.(1982, p. 4)

Alejados de una práctica literaria-intelectual comprometida con el entramado social a la manera en que esta era comprendida entonces por los dogmatismos de izquierda, pero sin caer por ello en el imaginario del "arte por el arte", la literatura que se promueve desde Sitio es una literatura que se percibe como transitando siempre los intersticios; una literatura, según lo plantea Jinkis (1981, p. 4), de deriva: "Los rodeos producen la impresión de una deriva, pero es que en los basurales el paisaje humano se vuelve más abigarrado y puede hacerse forzoso avanzar hasta con los codos". Aunque esto no significa, como advierte Maximiliano Crespi, que se trate de una praxis despolitizada: 
En Sitio, el valor político de una literatura no se deduce de la adscripción a una causa justa, sino de su capacidad de producir una afirmación ética capaz de poner en crisis todo aquello que se establece culturalmente por la 'acción rectora generalizada' de esa plancha de metal que hegemoniza sus instituciones. (2010, p. 179)

Sin embargo, ante la emergencia del conflicto bélico, surge la necesidad de replantear el rol de esa literatura tal como hasta entonces era concebida. Si el país, tras la guerra, estaba experimentando un cambio profundo ¿acaso la literatura no debería también cambiar?

En septiembre de 1983 se publica la tercera edición de Sitio en la que se incluye el texto La ilusión de unas islas $(1983)^{5}$ donde Néstor Perlongher, desde Brasil, responde al entredicho colectivo del número anterior. A su vez, en esa misma edición, Jorge Jinkis (1983) publica A la tibia musa, de un vate desencantado y Ramón Alcalde Ilusiones de isleño (1983), dos textos donde los directores de la revista salen a contestarle a Perlongher. En el intercambio, se producía fuego discursivo cruzado entre ambas trincheras apelando a un lenguaje esencialmente artístico que se alejaba del tono cientificista de otros documentos. Perlongher (1983, p. 47) disparaba sus argumentos en un lenguaje sumamente poético cargado de ironía contra lo que cree un "patriotismo infanto-juvenil acneico"; sentimiento históricamente reproducido en la institución escolar que parecía haber calado en los autores del entredicho, a los que caracteriza -lírica e irónicamente- como vates:

Se discute, se va a las manos, por la posesión de unos desiertos (de los que al parecer no puede desertarse). Se despierta, en el desierto, el vate: legañoso, ilusiónase: "la guerra -imaginábamos- nos dejaría en relaciones sociales nuevas (por momentos, las suponíamos triunfantes e inaugurales). (1983, p. 47)

La imagen de las islas como un desierto del cual no puede desertarse parece alcanzar en Perlongher tanto a soldados como a intelectuales y literatos. Nadie puede escapar, ni siquiera él, de ese territorio imaginario en disputa por el que se discute y se va a las manos. La guerra por el

\footnotetext{
${ }_{5}$ Perlongher ya había manifestado anteriormente su postura en contra de la guerra de Malvinas en otros dos textos. El primero, llamado originalmente Todo el poder a Lady Dy. Militarismo y anticolonialismo en la cuestión de las Malvinas, fue publicado en 1982 en el número 12 de la revista feminista Persona. El segundo, El deseo de unas islas, fue leído el 25 de junio de 1982 en el Sindicato de Jornalistas de São Paulo, en un encuentro sobre "Política y Deseo" organizado por grupos gays paulistas, y publicado recién en 1985 en el número 3 de la revista Utopía. Ambos textos y el publicado en la revista Sitio se encuentran recopilados en: Néstor Perlongher (1996): Prosa plebeya. Ensayos 1980-1992.
} 
territorio concreto ya ha finalizado con su saldo de bajas para ambos bandos, pero lo que parece seguir en juego es ese espacio simbólico que delimita el archipiélago en la cultura argentina y los sentidos atribuibles al conflicto bélico. Como hemos visto, para los directores de Sitio, la guerra fundaba una nueva etapa en la cual se impondrían relaciones sociales también nuevas. Es esa percepción, que Perlongher caracteriza como ilusoria e imaginaria de parte de los autores, la que él ataca con toda la potencia corrosiva de su ironía:

Empero, una ilusión (“con lo que acaso se logró ilusionarnos”) deviene "decepción” -y “objetiva” ¡Habíamos Sido Engañados! Los Vates- que nos preguntábamos qué función (...) "nos tocaría cumplir" en esas "nuevas relaciones" -nos reencontrábamos con "el cierzo de la derrota"- la "soledad esencial" del barranco. Ello tal vez nos ha salvado del dudoso oficio de, vestidas de chinas, y trenzadas, payar en los vivaques- "Ahora nosotros, en guerra, pasábamos a ser un hecho del que la literatura tendría que dar cuenta". De darse cuenta (o vuelta) nadie, en cambio, se salva. (1983, p. 47)

Los vates, los poetas -entre los que parece en principio incluirse para separarse luego, dado que él no se ha preguntado sobre la función que les tocaría cumplir en esas nuevas relaciones sociales-se han vistos engañados por el discurso triunfalista del régimen militar y se han desengañado, luego, una vez desencadenada la derrota en Malvinas. Perlongher los feminiza, los disfraza de chinas -"trenzadas" en discusiones y polémicas-, folclorizándolos y otorgándoles así un rol pasivo, enfatizado en la idea de darse vuelta. La capitulación, metaforizada sexualmente, los ha salvado de someterse aún más y tener que payar en los vivaques, de tener que cantar las loas del régimen militar. El darse vuelta también supone un cambio de posicionamiento de parte de quienes hacen Sitio, idea en la que el poeta va a insistir hacia el final de su texto al preguntarse: "La desalada guerra, ¿Nos ha cambiado el Sitio de lugar? ¿Lo ha acercado a unas islas? ¿Anclado en 'aguas territoriales'?” (1983, p. 48).

Por su parte, tanto Jinkis como Alcalde se hacen cargo del reposicionamiento. Este cambio se representa como resultado de las condiciones impuestas por la guerra; situación que los obliga a hablar, a pronunciarse y asumir un lugar desde el cual hacerlo:

Hablar Perlongher, no es quedarse en un lugar. Hablar es siempre cambiar de lugar, aunque esto no vuelve equivalentes a todos los lugares. Hay gente que busca el lugar, cree elegirlo, para luego echarse un parrafito. También hay gente que va a parar adonde la mandan sus palabras. (...) Si la revista ha "cambiado" 
de lugar, esto sólo significa que ha hablado... allí donde esperabas su silencio. Pero no "se ha dado vuelta" Perlongher (...). (JINKIS, 1983, p. 48)

En la perspectiva de Jinkis, asumir una postura y postular un cambio no implica "darse vuelta" para ser funcional a los discursos hegemónicos. Puede leerse entre líneas en la respuesta una diferenciación de los lugares desde donde se emite cada discurso: Perlongher, desde su exilio brasilero. Ellos, en la Argentina. Esta diferencia es marcada más tajante y explícitamente por Alcalde en su respuesta, una vez que reconoce el cambio de posicionamiento:

\footnotetext{
Es verdad. Cambiamos. En parte, nos cambiaron; pero, mucho más, quisimos cambiar o dejarnos cambiar. Si no lo hacíamos, nos quedábamos solos. Solos de quienes nos interesan. De lectores reales o imaginados. Solos, en esa monserga del "exilio interior", de la "catacumba", novedosísima argucia, que no define nunca el lugar de la expulsión (o del irse a baraja); una especie de jubilación reversible, de la que afloraremos algún día, "los puños llenos de verdades" (...) Y mucho mejor legitimados por nuestro martirologio que los mersas eyectados hacia los Pontos no tan brumosos de París, Barcelona, Río de Janeiro, M.I.T, México DF. (1983, p. 53)
}

Asegura Alcalde que si los escritores de Sitio han cambiado, lo han hecho para no quedarse sin lectores, para no aislarse aún más de lo que ya se encontraban en un campo intelectual que había sufrido las operaciones represivas de la dictadura. El aislamiento supone una especie de exilio interior que los ubica dentro del país, pero fuera del campo cultural, o bien, en un campo que se ha vuelto inocuo dentro la sociedad. Si bien al referirse a la propia condición en términos de exilio pareciera homologarla con respecto a la de Perlongher, luego establece una jerarquización: ellos, los que se quedaron en la Argentina, se encuentran mucho mejor legitimados que todos aquellos que partieron al exilio. No es casual que la revista retome en este punto la discusión acerca de los que se fueron/los que se quedaron; tópico que había gravitado con fuerza en los primeros años del régimen militar evidenciando las fracturas del campo intelectual. De hecho, estos entredichos no nombrados como tales en la publicación, se integran en un anexo de la edición denominado "Del exilio". Ante el inminente retorno de la democracia y, con ello, el regreso al país de la mayoría de los intelectuales y escritores que se habían vistos forzados a irse durante la dictadura, los autores de Sitio intentan caracterizar un discurso del exilio. Al hacerlo, los escritores de la revista se diferencian de los que se fueron y generan así operaciones de pertenencia y exclusión 
en un campo que, entienden, se encuentra en proceso de cambio. En su contrataque argumental, Alcalde no sólo se (auto)legitima, sino que procede a desterrar a Perlongher de cualquier pertenencia simbólica a la nación. Alcalde lo aísla, en el sentido de separarlo para ubicarlo, en soledad, en una isla; isla que no es, precisamente, Malvinas:

(...) Perlongher, retrotraído a un Estado en el que no está; si no mira a su alrededor, ni se dará cuenta del Escuadrao, de Macunaima, de Joao das Mortes Matador do Cangaceiro. No necesitará correr como nosotros, iluso, tras imposibles ilusiones de "relaciones sociales nuevas". Fuera de su Estado (el de su pertenencia originaria), escribe como si estuviera fuera de todo Estado. (...) No vivió nuestras ilusiones. Tampoco el odio, la humillación, el dolor reales, que vivimos los de Sitio. Manténgase en su ínsula, Perlongher con su ilusión extraterritorial, pero acepte, aunque más no sea como hipótesis, que podamos haber cambiado, y no por mala fe. (1983, p. 55)

En el discurso de Alcalde, Perlongher es un paria. Lo representa como desterritorializado, fuera de todo Estado, aislado en su ínsula literaria -que no es argentina, pero tampoco brasilera-, relegado en una especie de no lugar. De ahí que no comparta las ilusiones de los autores de Sitio, ni sus expectativas respecto a las nuevas relaciones sociales. Él no las necesita; ellos, en cambio, sí. Pero ¿cuál es el fundamento de esas ilusiones? Alcalde las explicita, aunque las asume como propias y no las hace extensivas al resto de sus compañeros de revista:

Mis personales ilusiones sobre la guerra, en las cuales, sin embargo, sé que no estoy solo, son dos: 1) cualesquiera hayan sido las intenciones, las circunstancias y el modo como se la inició y se la llevó a cabo, la guerra pudo ganarse y estuvo a punto de ser ganada, pero fue vendida; 2 ) esta guerra entre un país dependiente y las dos mayores potencias imperialistas, más sus aliados de la NATO, implicaba forzosamente la aparición de condiciones sociales nuevas. Pude creer que las condiciones serían promovidas, lo más limitada y contradictoriamente que fuera, por quienes estaban conduciendo la guerra. Pero lo creí porque imaginé -sobre todo en las fases iniciales- que la guerra se iniciaba para no perderla. Puedo haber sido ingenuo. Pero esto no me parece lo importante. Sí, en cambio, que las nuevas condiciones están dadas, y que lo están como consecuencia no querida de la guerra. Que se las desarrolle o se las aborte (o que se las intente abortar) es algo que ya no depende del triunvirato que decidió la invasión. Depende de todos los argentinos. De lo que políticamente hagamos. (1983, p. 56)

Las ilusiones de Alcalde se fundan entonces en la posibilidad concreta de una victoria militar argentina. Aunque no aclara cómo "fue vendida" la guerra, está convencido, siguiendo la información que tiene acerca del desarrollo del conflicto, de que algunos cambios en las variables bélicas 
hubiesen significado el triunfo del ejército argentino. Sin embargo, lo verdaderamente importante es que, aún con la derrota como resultado, se han dado las condiciones que permitirán esas anheladas nuevas relaciones sociales. Los escritores de Sitio creen que la guerra supondrá la emergencia de relaciones sociales nuevas en el país; circunstancia que los lleva a replantear su papel en el campo cultural. Si bien el fracaso de la recuperación de Malvinas significa la frustración de esas ilusiones, se trataría sólo de un fracaso parcial de sus expectativas, ya que es la guerra -independientemente de su resultado- el episodio que determinará la restitución de la democracia y, con ella, la emergencia de nuevas relaciones sociales. De acuerdo con la perspectiva de Alcalde, en estas circunstancias, son ellos -los escritores e intelectuales que permanecieron en el país durante la dictadura y la guerra- quienes resultan mejor legitimados en un nuevo contexto democrático.

Si Perlongher había atacadoesas ilusiones como ingenuas-ingenuidad que, por cierto, Alcalde termina reconociendo-, caracterizando a los directores de la revista como vates engañados por el discurso hegemónico y luego desilusionados por la realidad del fracaso bélico, lo hace porque entiende que en la Argentina hubo dos guerras signadas por la misma lógica de la violencia estatal: la guerra "limpia" de Malvinas y la guerra "sucia” que el régimen militar había denominado como guerra antisubversiva:

\footnotetext{
El Entredicho se eleva fugazmente al didactismo, cuando revela que el Estado Argentino -"espectador neutral"- no ha conocido, en este siglo, guerras. Debe referirse, pensamos, a las guerras "limpias" (libradas, según las reglas de las artes marciales, entre Estados Soberanos). Soberanos, nos tienta. Pero no hay por qué suponer -en honor al localismo- que el fango de las trincheras de Ganso Verde ensucie, o manche, más, que el barro de las zanjas de Victoria, o el Tigre. Sólo que en el primer caso la pantera bélica ruge más estentórea, sin clandestinidad aparente. Lo que velaba, empero, la retórica es -y, peor, era- ya manifiesto. (PERLONGHER, 1983, p. 47)
}

Perlongher les recrimina a los autores del "Entredicho" colectivo haber omitido en su texto la mención de esa otra guerra, la de la represión y las desapariciones del terrorismo de Estado. Si bien, en principio, las diferencia en su caracterización (sucia/limpia), termina por equiparar a ambas como guerras sucias: el fango del campo de batalla en Ganso Verde (Goose Green, locación de las islas Malvinas) mancha tanto como el de las zanjas de los centros de detención clandestinos en la Argentina continental. Por su parte, tanto Jinkis como Alcalde van a defenderse de 
ese argumento que pareciera condenarlos como funcionales al discurso del régimen militar y lo hacen criticando como falsa la analogía de Perlongher:

Homologar, y contra tus propias palabras, "el fango de Ganso Verde" con "el barro de Victoria", es aplastar lo mismo contra lo mismo desconociendo todas las diferencias, es apoyar la moralidad de la alegoría en la oposición "limpio/ sucio", y es incluir lo "manchado", estremecedor escándalo, en los dominios ahora extendidos del Bien. ¿Todas las guerras, la guerra? Pero no toda es vigilia, la de los ojos abiertos. Ni poesía un verso que se quiere despierto. (JINKIS, 1983 , p. 50)

Por su parte, Ramón Alcalde le responde a Perlongher en un tono más personal, dejando entrever que las condiciones de enunciación -la Argentina de la dictadura- no le permiten aludir a la "guerra sucia":

Por ahora, Perlongher, no voy a hablar de esa guerra que usted dice que obliteramos. Pero le propongo un trato. Usted viene a Buenos Aires y explica públicamente las coincidencias que ve entre Prado del Ganso (o Ganso Verde) y Tapiales o Azul. Me comprometo a exponer mi punto de vista en igual número de páginas, para ver si y en qué discrepamos al respecto. Pero con una condición: usted me presta por un tiempo su deptito de Sao Paulo, por si las Tres Moscas. ${ }^{6}$ (1983, p. 55)

En la lógica de los autores de Sitio, Perlongher unifica ambas guerras en una analogía errónea porque sólo tiene una experiencia parcial experiencia de la dictadura, pero no del conflicto bélico ${ }^{7}-$, lo que le impide percibir las diferencias entre ambos episodios; sucesos que ellos, en cambio, han vivido en el lugar de los hechos. Pero ese posicionamiento es más simbólico que territorial. La guerra de Malvinas transcurrió geográficamente lejos de donde se encontraban los autores de Sitio, casi tanto como se encontraba Perlongher. La diferencia radica en que ellos no sólo han sentido en carne propia el clima bélico que se vivió en el país, sino, principalmente, en que no han abjurado de su pertenencia nacional. En cambio, desde la revista, Perlongher es el eyectado, el que se ubica fuera de una nación a la que parece haber renunciado.

\footnotetext{
${ }^{6}$ Las Tres Moscas que menciona Ramón Alcalde hace referencia claramente a los aparatos represivos del Estado: la llamada Triple A -Alianza Anticomunista Argentina- o bien, las tres Fuerzas Armadas.

7 Perlongher partió en 1981 de la Argentina a Sao Paulo, Brasil; donde vivió hasta el momento de su muerte en 1992. En enero de 1976 había sido procesado y detenido por su militancia en el Frente de Liberación Homosexual Argentina, una asociación de defensa de los derechos homosexuales de tendencia izquierdista y revolucionaria.
} 
En sus respuestas, los directores de Sitio no sólo cuestionan el posicionamiento de Perlongher buscando deslegitimar su posición a partir de apelar a su condición de exiliado, lo que supone una crítica política. También hay en los textos de Jinkis y Alcalde un cuestionamiento formal donde se apunta a lo estrictamente literario. En primer lugar, los autores de la revista acusan al poeta de no haberlos leído correctamente, ya que entienden que no ha sabido interpretar la ironía presente en el enunciado de ese primer "Entredicho" colectivo; como resalta Jinkis:

Cuando se le confía el argumento a la ironía, se extiende esa confianza a la lectura. Es esperable que el lector discrepe, o rechace el modo, o conceda a la ironía un lugar inesperado para aquel que escribe. Pero también es esperable que el lector lea la ironía. Dos veces Perlongher la ha dejado pasar inadvertida. (...) Su imaginación lo ausenta de esa figura que llamamos "lector": lamentable, pues lectura es el nombre de ese sitio que haría posible hablar entre nosotros. (1983, p. 5o)

En segundo lugar, critican la forma que asume su respuesta, ya que caracterizan al estilo literario de Perlongher como "frívolo". Para ellos, el escritor se resguarda en un lenguaje poético e irónico que lo exime de exponer claramente su posición respecto a la guerra; lo que es percibido por Jinkis (1983, p. 49) como un afectado gesto transgresor: "De tantas morisquetas, la cara se llena de tics. Hay un tic de la vanguardia que se llama ‘transgresión”'. Por su parte, Alcalde explicita su rechazo al código político, ético y estético que vislumbra en Perlongher y la forma literaria que este elige para manifestar su postura; de ahí que, como contraste, opte por un estilo mucho más directo y argumentativo para responderle:

\begin{abstract}
A esta técnica de Perlongher quiero que mi texto oponga una escritura algo más estructurada, que me dificulte (y dificulte a los lectores) tirar la piedra y esconder la mano o puentear el audífono. No es por caridad. Perlongher no la necesita ni la merece, sino porque cuestiono su código político, ético y estético, que es quien le recomienda o prescribe la forma que eligió. Pero más que nada porque lo de Malvinas sigue siendo para mí algo demasiado patético como para resbalarme hacia lo que -desde mis referencias- no puedo sentir sino como frivolidad. (1983, p. 52)
\end{abstract}

En tiempos en los que, como asegura Josefina Ludmer (2010), las identidades literarias suponen a su vez identidades políticas, Alcalde entiende a la postura política y a la estética literaria de Perlongher imbricadas ambas en su texto- como desatinadas para el contexto de la postguerra. Ante lo dramático del conflicto bélico, una prosa corrosivamente sarcástica como la del poeta es sentida como demasiado 
superficial y banal. Sin embargo ¿no era acaso esa literatura que se describía como "intersticial", "cifrada” y "ladina” la que se promovía desde las páginas de Sitio en los comienzos de la publicación? Precisamente en este punto es donde la revista revela su voluntad de cambio. Tanto en el "Entredicho" colectivo como en la respuesta de Jinkis a Perlongher se manifiesta claramente una necesidad de cambio en el campo cultural y en las formas literarias, pero no se explicita cómo es que deben cambiar. La cuestión se plantea en clave de interrogante y no de respuesta. Podría llegar a especularse con que los autores de la revista postulan el abandono de esa literatura evasiva, de deriva, por una más comprometida con la realidad social, pero Alcalde descarta esa posibilidad para proponer, en cambio, un retorno al tono de lo trágico:

No sonreíd tan pronto, alacranes: no es que propicie ningún retorno enmoralizante al "compromiso social y político de la literatura", no me precipito a la más cercana Mesa de Trabajo. Tampoco quisiera adoctrinar a nadie. Opino, nomás, que la literatura en la Argentina (o algunos escritores argentinos a los que les interese) tenemos que aprender o reaprender, a ser trágicos, si no queremos terminar en bufonescos. (1983, p. 53)

Si bien la propuesta no es adscribir al realismo de tipo socialista que se postulaba como modelo a seguir por algunas corrientes de la izquierda durante las décadas del 6o y del 7o, el texto de Alcalde incluye el testimonio de Daniel, un conscripto clase 1963 sobreviviente del hundimiento del Crucero General Belgrano. La presencia del breve relato testimonial se justifica por el escritor al establecer a Daniel como caso paradigmático de la emergencia de un nuevo grupo de lectores: el de los sobrevivientes, grupo que incluye a los soldados de Malvinas, como también a los torturados y los mutilados (él no dice por quién, pero puede suponerse que tanto por la guerra como por la dictadura). Alcalde no dice que hay que escribir sobre Daniel -aunque lo hace-, sino para él y cree que la mejor manera de hacerlo es desde la gravedad de lo trágico y no desde el lirismo irónico de Perlongher. Para poder hacerlo, es decir, para hacer literatura destinada a los sobrevivientes, la experiencia, a su entender, tendrá un rol determinante. Así como la experiencia de la guerra -que los autores de Sitio poseen y Perlongher no- era una instancia legitimadora del posicionamiento político considerado correcto, también lo será para encontrar la forma más adecuada -ese tono trágico que Alcalde postula- de escribir para esos nuevos sujetos sociales de la postguerra y la postdictadura: 
En este camino de acceso o de recuperación de lo trágico, sin cuya presencia no conozco literatura nacional que haya ascendido al interés y la perduración universales, los escritores argentinos de 1976-1983 tienen una ventaja: la de haber sido sumidos y haber quedado atrapados en la tragicidad transubjetiva de una historia que parece cerrada como destino de deshumanización. El Proceso, Malvinas, y (aunque no quiero ser grajo de mal agüero) todo lo que nos queda por pasar. (1983, p. 54)

Alcalde procede nuevamente a legitimarse y a legitimar no solo su grupo de procedencia, el de la revista Sitio, sino también el de los escritores que permanecieron en el país, en una operación que proscribe -a Perlongher y también a aquellos exiliados que no poseen la experiencia del Proceso militar y de Malvinas- y, a la vez, prescribe: un género, un código, un lenguaje literario apropiado para el nuevo contexto de la Argentina. Si bien el escritor entiende esa etapa, la de la transición entre la derrota militar en Malvinas y el advenimiento de la democracia, como una etapa de búsqueda artística, establece una jerarquización donde pondera lo trágico como el género que puede enaltecer a la literatura argentina y concederle un valor universal, mientras que lo cómico, lo irónico, lo sarcástico quedaría relegado como marginal y bufonesco. A su vez, desde su lógica, los escritores que han vivido en el país durante el régimen militar corren con una ventaja frente al resto: son poseedores de una experiencia histórica trágica, por lo tanto, la tragedia les resultará un género tan apropiado como familiar.

\section{A MODO DE CONCLUSIÓN}

Lo que denomino trincheras intelectuales se constituyen como espacios desde los cuales se defienden -y también se atacan- posiciones políticas y estéticas. Si bien la discusión acerca de Malvinas no nace con la guerra de 1982, ante la emergencia del conflicto bélico surgen posiciones que no tardan en confrontar. Se trata de una disputa de sentidos que tiene al terreno imaginario de la nación como escenario bélico simbólico. Polémicas que asumen el carácter subjetivo y dialógico del ensayo donde se ponen en juego posicionamientos dentro del campo intelectual. Como hemos visto, las principales operaciones de los actores inmersos en esas trincheras/posiciones son de pertenencia y exclusión en relación a esa nación imaginada. Esa lógica que delimita un adentro y un afuera atraviesa la batalla de discursos que se establece entre los autores de la revista Sitio y Néstor Perlongher. Los editores de la revista postulan la pertenencia 
concreta -territorial y geográfica- como instancia legitimadora. Mientras representan al poeta como un desterrado, los escritores de Sitio se constituyen como portadores de una experiencia que los legitima dentro del nuevo campo artístico e intelectual de la postdictadura. El ataque dirigido a la condición de exiliado de Perlongher puede entenderse, a su vez, como una acción defensiva de una posición dentro del campo que se ve amenazada por el inminente regreso de los escritores que volverán al país con el restablecimiento de la democracia. La batalla se desarrolla entonces en ese contexto de reconfiguración del campo; coyuntura donde los autores manifiestan la consciente necesidad de adoptar formas y lenguajes literarios nuevos. Es por eso que los integrantes de la revista -en la voz individual de Ramón Alcalde- prescriben una forma literaria a la que presentan como la más adecuada tras el episodio de Malvinas: la tragedia. De acuerdo con esta postura, cuando la literatura asuma la reescritura de la guerra, deberá hacerlo con el tono grave y solemne de lo trágico, porque la risa se concibe como un gesto literario impropio del drama bélico que había calado tan profundo.

En un principio, podría pensarse que este tipo de polémicas significaron el origen de un debate más profundo dentro del campo intelectual argentino acerca del episodio histórico de Malvinas. No sólo por la trascendencia política y social del suceso bélico y sus consecuencias, sino también por la inminente apertura y expansión del campo intelectual ante el restablecimiento del orden democrático. Aquellas voces que se habían visto acalladas en el contexto represivo de la dictadura podían ahora manifestarse abiertamente, asumir posturas críticas y establecer discusiones acerca de lo que había significado la guerra. Sin embargo, contrariamente a estas expectativas, durante el período inmediatamente posterior al conflicto bélico, los debates más gravitantes fueron los que se interesaron en revisar el pasado reciente para discutir, sobretodo, la experiencia del terrorismo de Estado y la derrota del ideario revolucionario de izquierda, a la vez que proyectaban un análisis sobre el futuro de la nueva etapa democrática que recién se inauguraba. El episodio de Malvinas quedó así como una especie de hiato entre la revisión del pasado de la dictadura y la reflexión respecto del horizonte promisorio de la democracia. El análisis de lo sucedido durante el conflicto bélico, así como el de sus secuelas traumáticas no sólo quedaron relegados de los principales temas de debate del comienzo de la postdictadura, sino que tampoco hubo autocrítica dentro del campo intelectual respecto a 
las posturas asumidas al momento de la guerra. En este sentido, podemos pensar que la cuestión Malvinas no encontró condiciones de audibilidad suficientes en el contexto antibelicista de la democracia emergente porque se trataba de un asunto que suponía una revisión crítica del rol desempeñado tanto por los distintos sectores sociales como por aquellas zonas del campo intelectual que en cierta forma acompañaron y legitimaron la recuperación militar de las islas.

\section{REFERENCIAS}

ALCALDE, Ramón. (1983). Ilusiones de isleño. Sitio. número 3. septiembre de 1983. pp.5259 .

ALCALDE, Ramón. et. al. (1982). Las Malvinas argentinas. Del trabajo a la guerra y de la guerra al trabajo. ¡Argentinos a recomponer!.Sitio. número 2. noviembre de 1982. pp.3-8.

BORGES, Jorge Luis. (1982). Juan López y Juan Ward. Disponible en: http://www.poesi.as/ jlbi34o.htm

BOURDIEU, Pierre. Campo de poder, campo intelectual. Itinerario de un concepto. Buenos Aires: Montressor jungla simbólica, 2002.

BROCATO, Carlos. (1982).¿La verdad o la mística nacional?. En: Suárez, Carlos Abel. Malvinas: el crimen, la guerra y el simulacro, 25 años después. Sinpermiso. 1 de abril de 2007. Disponible en: http://www.sinpermiso.info/textos/malvinas-el-crimen-laguerra-y-el-simulacro-25-aos-despus.

BUENO MARTÍNEZ, Gustavo. (1966). Sobre el concepto de ensayo. Universidad de Oviedo, tomo 1, 1966, pp. 89-112. Disponible en: http://www.filosofia.org/aut/gbm/1964ensa. htm.

CRESPI, Maximiliano. Sitio: entre la guerra de Malvinas y la ley de Obediencia Debida. En: Carbone, Rocco y Ojeda, Ana (comp.), De Alfonsín al menemato (1983-2001). Buenos Aires: Paradiso, 2010, pp. 176-189.

ESTÉBANEZ CALDERÓN, Demetrio. Diccionario de términos literarios. Madrid: Alianza, 1996.

JINKIS, Jorge. (1983). A la tibia musa, de un vate desencantado. Sitio. número 3. septiembre de 1983. pp. 49-51.

LUDMER, Josefina. (2010). Aquí América Latina. Una especulación. Buenos Aires: Eterna Cadencia, 2010. 
PATIÑO, Roxana. (2006). Revistas literarias y culturales argentinas de los 8o. Ínsula. número 715-716. julio-agosto de 2006. Disponible en: http://www.revistasculturales. com/articulos/37/insula/596/1/revistas-literarias-y-culturales-argentinas-delos-8o.html.

PAVÓN, Héctor. (2008). Los que se fueron y los que se quedaron. Revista $\tilde{N} .22$ de marzo de 20o8. Disponible en: http://edant.revistaenie.clarin.com/notas/2008/03/22/01632943.html.

PERLONGHER, Néstor. (1983).La ilusión de unas islas. Sitio. número 3. septiembre de 1983. pp. 47-48.

PERLONGHER, Néstor. (1996). Prosa plebeya. Ensayos 1980-1992. Buenos Aires: Colihue, 1996.

ROSSLER, Osvaldo. (1982). Cambalache. Disponible en: http://oldplasticface.blogspot. com.ar/2010/o2/cambalache-1982.html

ROZITCHNER, León. (1985). Malvinas: de la guerra sucia a la guerra limpia. Buenos Aires: Losada, 2005.

SARLO, Beatriz. et. al. (1982). Paz inmediata y negociación: única victoria del pueblo. En: Sarlo, Beatriz. Viajes. De la Amazonia a las Malvinas. Buenos Aires: Seix Barral, 2014, pp. 251-260.

SARLO, Beatriz. (1988). El campo intelectual: un espacio doblemente fracturado. En: Sosnowski, Saúl. (comp.), Represión y reconstrucción de una cultura: el caso argentino. Buenos Aires: Editorial Universitaria de Buenos Aires, 1988, pp. 96-108. 